\title{
PERANCANGAN SISTEM KENDALI PADA LENGAN ASSISTIVE SOCIAL ROBOT MENGGUNAKAN KAMERA
}

\author{
Riky Tri Yunardi ${ }^{*}$ dan Ronny Mardiyanto ${ }^{2}$ \\ ${ }^{1}$ Departemen Teknik, Fakultas Vokasi, Universitas Airlangga \\ ${ }^{2}$ Departemen Teknik Elektro, Fakultas Teknologi Elektro, Institut Teknologi Sepuluh Nopember \\ "Corresponding author, e-mail: rikytriyunardi@ vokasi.unair.ac.id
}

\begin{abstract}
Abstrak-Teknologi robotika telah banyak diaplikasi dan dikembangkan dalam bidang rehabilitasi. Assistive Social Robot merupakan suatu teknologi robotika yang dapat berinteraksi dengan pengguna dan memberi bantuan dalam pemulihan proses rehabilitasi. Aksesibilitas ketika mengambil sebuah benda dengan menggunakan sistem lengan robot sangat dibutuhkah. Kamera merupakan sensor optik yang paling banyak diaplikasikan untuk mendeteksi posisi objek. Artikel ini membahas mengenai sistem kendali lengan robot menggunakan kamera. Informasi jarak dan posisi objek digunakan untuk mengendalikan gerakan lengan robot robot yang berbentuk gripper. Pengujian yang dilakukan meliputi: pengujian mendeteksi kontur objek, pengujian pengukuran jarak objek, serta pengujian kendali lengan robot. Dari hasil menunjukkan kecepatan kinerja sistem kendali yang telah dirancang dalam melakukan tugas untuk mengambil sebuah objek dari posisi awal sampai akhir memerlukan waktu 28,05 detik.
\end{abstract}

Kata Kunci : Assistive social robot, lengan robot, kamera

\begin{abstract}
Robotics technology has widely applied and developed in the rehabilitation field. Assistive Social Robot is a technology that can interact with users and improve progress in rehabilitation. Accessibility when taking an object using a robotic arm system is needed. A camera is the optical sensor that has been applied to detect the position of the object. In this paper explain a design of control system of robotic arm by using a camera. Information of the distance and position are used to organizing the control of the robotic arm movement, that form of a gripper. Tests conducted include: testing to detect the contour of the object, testing the measurement of object distance, and testing the robot arm control. From the results shows the speed of performance of control system that has been designed in performing the task to pick up an object from the initial position to the end takes 28.05 seconds.
\end{abstract}

Keywords : Assistive social robot, robotic arm , camera

Copyright $@ 2017$ JNTE. All rights reserved

\section{PENDAHULUAN}

Teknologi robotika telah banyak diaplikasi dan dikembangkan dalam berbagai bidang salah satunya dalam bidang rehabilitasi. Berdasarkan data dari U.S. Department of Commerce Bureau of the census [1] keterbatasan kemampuan fisik yang dialami oleh manusia dalam menjalankan aktivitas sehari-hari antara lain: berjalan, makan dan minum, mandi, menyiapkan makanan atau mengerjakan pekerjaan rumah ringan lainnya. Assistive social robot merupakan suatu teknologi yang dibuat untuk menghasilkan suatu sistem robot yang dapat berinteraksi dengan pengguna secara efektif dalam memberi bantuan dan meningkatkan kemajuan dalam pemulihan atau rehabilitasi [2].

Beberapa aplikasi sistem Assistive social robot diantaranya untuk kebutuhan orang tua dalam memberikan bantuan mobilitas dan memantau tanda-tanda vital tubuh [3], robot penuntun dengan navigasi antara manusia yang dapat mendeteksi halangan di depan [4] dan untuk meningkatkan aksesibilitas ketika mengambil sebuah benda dengan menggunakan sistem lengan robot [5].

Berdasarkan uraian di atas maka pada makalah ini akan dibahas tentang perancangan sistem kendali lengan robot yang dapat mendeteksi posisi dan mengestimasi jarak sebuah objek menggunakan kamera.

\section{TINJAUAN PUSTAKA}

Terdapat beberapa penelitian yang berhubungan dengan assistive social robot 
dengan berbagai bidang penelitian yang telah dilakukan. Sebuah konstruksi lengan robot yang dibangun untuk aplikasi mengambil dan memindahkan sebuah bola berwarna telah dibahas oleh Huang [6]. Proses estimasi posisi objek dilakukan berdasarkan pendeteksian tepi permukaan objek.

Jenis robot asistive yang telah diteliti untuk membantu mobilitas bagi pengguna yang pada umumnya merupakan orang yang telah berumur antara lain Cre-O-Bot oleh Graf [4] dan PAMM oleh Spenko [3] yang memiliki ukuran atau ketinggian hampir setinggi jangkauan tangan. Dalam perkembangnya sebagai smart walker ditambahkan serangkaian sensor ultrasonik untuk mendeteksi halangan yang derada di depannya sehingga dapat berhenti sendirinya untuk mencegah terjadinya tumbukan.

Yanco [7] dan Simpson [8] telah melakukan penelitian robot mobile autonomous yang pada umumnya berupa kursi roda listrik. Robot ini digunakan bagi pengguna yang memiliki keterbatasan gerak pada kakinya. Bagi pengguna yang memiliki keterbatasan pada gerakan tangan oleh Topping [9] ditambahkan sebuah manipulator arm yang digunakan untuk mengarahkan makanan mendekati mulutnya ketika sedang makan yang bernama Robot Handy I.

Salah satu penelitian lain tentang lengan robot lain dengan menggunakan platform lengan robot STAIR (STanford AI Robots), telah dikembangkan oleh Saxena [10] pada aplikasi untuk meletakkan berbagai macam peralatan makan pada rak dengan berbasis visual menggunakan kamera untuk menentukan lokasi bendanya. Sebuah metodologi yang berbasis umpan balik visual untuk melakukan tugas mengambil dan meletakkan benda juga telah dikembangkan oleh Kouskouridas [11]. Dalam mengestimasi posisi objek melibatkan hubungan antara gambar dalam bidang 2D.

Wang [12] dan Song [13], membahas penelitian pada sistem hand-eye robot mengunakan informasi visual dari dua buah kamera. Metoda yang digunakan untuk memisahkan antara posisi objek dengan latar belakang menggunakan kombinasi edge detection dan color segmentation yang dianggap cukup efektif.

Grebenstein [14] dan Sancez-Lopez [15], membuat sebuah penelitian pada sistem lengan robot yang dapat mendeteksi possisi sebuah objek menggunakan kamera. Oleh Sherma, pengujian yang telah dilakukan untuk mendeteksi benda yang bergerak dan mengirim data pada sistem lengan robot menggunakan algoritma mean shift. Sedangkan Sancez-Lopez menggunakan color segmentation untuk mengklasifikasi benda yang dipilih dan mengatur gerakan end-effector-nya menuju benda tersebut.

\section{METODOLOGI}

\subsection{Spesifikasi Prototipe Assistive Social Robot}

Pada penelitian ini menggunakan sebuah prototipe assistive social robot yang telah dilengkapi sebuah lengan robot yang bekerja pada cylindrical coordinat. Manipulator yang digunakan untuk menggambil sebuah benda menggunakan lengan robot yang ujungnya ditambahkan dengan gripper sebagai alat penggenggam. Gripper merupakan sebuah tool yang diletakkan pada end-effector pada lengan robot berfungsi untuk menggenggam objek yang akan diambil. Pada bagian shoulder dapat bergerak translasi ke atas dan bawah, sehingga dapat digunakan untuk mengambil sebuah objek di atas meja dengan tinggi meja yang bermacammacam. Prototipe assistive social robot ditunjukkan pada Gambar 1.

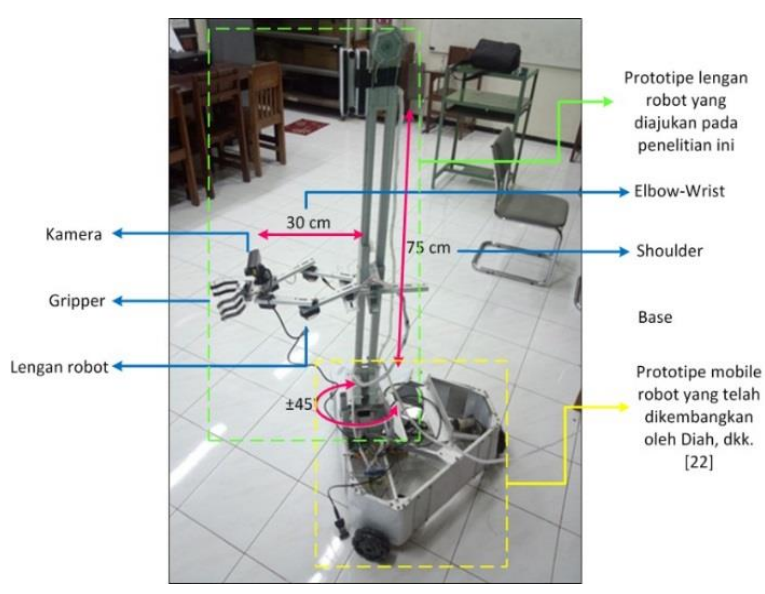

Gambar 1. Prototipe assistive social robot

Kamera digital yang digunakan adalah PSeye camera. Kamera ini memiliki keunggulan dari kecepatannya yang dapat mendukung frame rate hingga 75 fps pada resolusi VGA $(640 \mathrm{x}$ 480) dan sampai $120 \mathrm{fps}$ pada resolusi QVGA (320 x 240). Kamera diletakkan pada end- 
effector lengan robot seperti yang ditunjukkan pada Gambar 2.

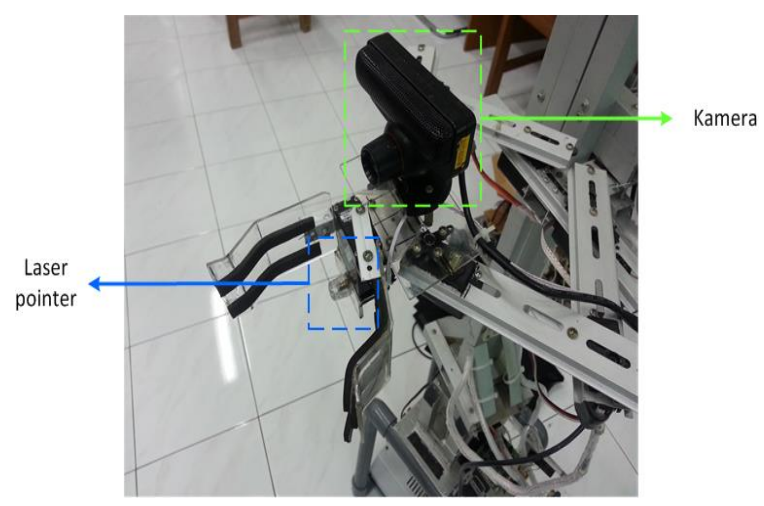

Gambar 2. Peletakan kamera pada end-effector lengan robot

\subsection{Perancangan Deteksi Bentuk Objek}

Metode pendeteksian berbasis kontur adalah algoritma pendeteksian yang melacak objek berdasarkan kontur objek dan memperbaharui kontur tersebut pada frame beturut-turut. Untuk mendapatkan hasil yang sesuai dengan yang diharapkan, maka dibutuhkan beberapa proses pengolahan citra.

Pada proses segmentasi posisi objek dari latar belakangnya dapat dilakukan dengan cara dengan menetukan nilai threshold untuk menentukan wilayah permukaan objek. Hal ini digunakan untuk mempermudah dalam proses selanjutnya ketika mencari kontur melalui binary image. Segmentasi dengan menggunakan thresholding sangat dipengaruhi oleh masalah pencahayaan, oleh karena itu perlu dilakukan pengkonversian dari ruang warna RGB menjadi HSV.

Proses selanjutnya proses segmentasi objek dari latar belakannya yaitu dengan menetukan nilai threshold untuk menentukan wilayah permukaan objek. Melaui citra HSV yang telah dihasilkan, objek dipilih menggunakan mouse click pada tampilan layar monitor. Dengan mendapatkan masing-masing nilai hue, saturation dan value pada satu titik piksel permukaan objek, dengan memberikan ambang batas maksimum dan batas minimum, dalam perancangan ditentukan nilai threshold maksimum dan minimum sebesar 30 . Piksel warna yang memiliki nilai di dalam batas ambang akan diubah menjadi warna putih, sedangkan di luar nilai tersebut akan diubah menjadi warna hitam. Sehingga akan didapatkan hasil gambar berupa binery image $\mathrm{g}(\mathrm{x}, \mathrm{y})$ yang mempresentasikan sebuah luasan suatu objek.

Dalam proses thresholding, hasil yang yang didapatkan masih banyak mengandung derau atau noise yang dapat berupa titik-titik piksel seperti Gambar 3.

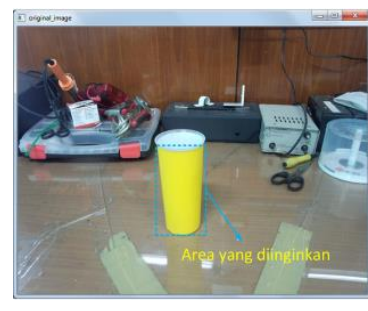

Gambar 3. Hasil proses mengandung derau

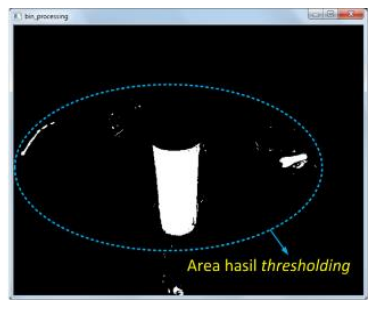

thresholding
Proses deteksi kontur dilakukan setelah proses segmentasi dilakukan dan mendapatkan luasan permukaan objek yang dipilih. Setelah itu diteruskan untuk ditemukan setiap kontur yang ada pada citra digital. Namun dalam proses segmentasi terdapat beberapa luasan yang tidak hilang dalam proses filtering. Sehingga ketika dilakukan pencarian kontur, seluruh luasan tersebut akan membentuk kurva yang terbentuk dari kumpulan titik-titik piksel menggunakan pendekatan tepi seperti yang ditunjukkan pada Gambar 4.

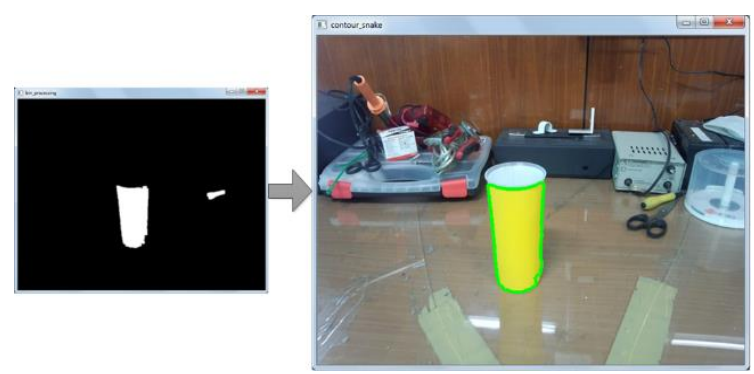

Gambar 4. Hasil proses deteksi kontur permukaan objek

\subsection{Pendeteksian Posisi Objek}

Untuk mendeteksi posisi objek yang berada diatas meja, gambar yang di-capture kamera yang telah terpilih menggunakan mouse click akan dideteksi posisi koordinat dan ukurannya menggunakan deteksi kontur. Posisi koordinat dan ukuran objek tersebut akan dijadikan sebagai informasi penentuan posisi $\mathrm{x}$ dan y objek tersebut. Dalam proses pendeteksian posisi objek perlu diketahui titik koordinat paling kiri, 
kanan, atas dan bawah dari kontur yang telah terbentuk. Dengan mengetahui titik-titik tersebut dapat diperoleh dengan sebuah bounding box.

Dari keempat posisi koordinat tersebut diproses kembali untuk mencari titik tangah atau koordinat piksel yang berada di tengah objek seperti yang ditunjukkan pada Gambar 5 .

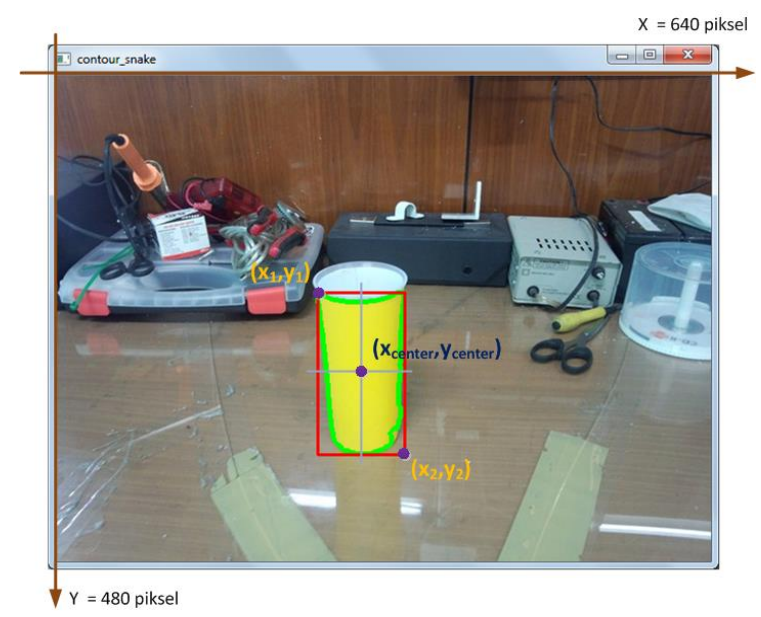

Gambar 5. Proses penentuan posisi $x$ dan $y$ objek

\section{HASIL DAN PEMBAHASAN}

\subsection{Pengujian Mendeteksi Kontur Objek}
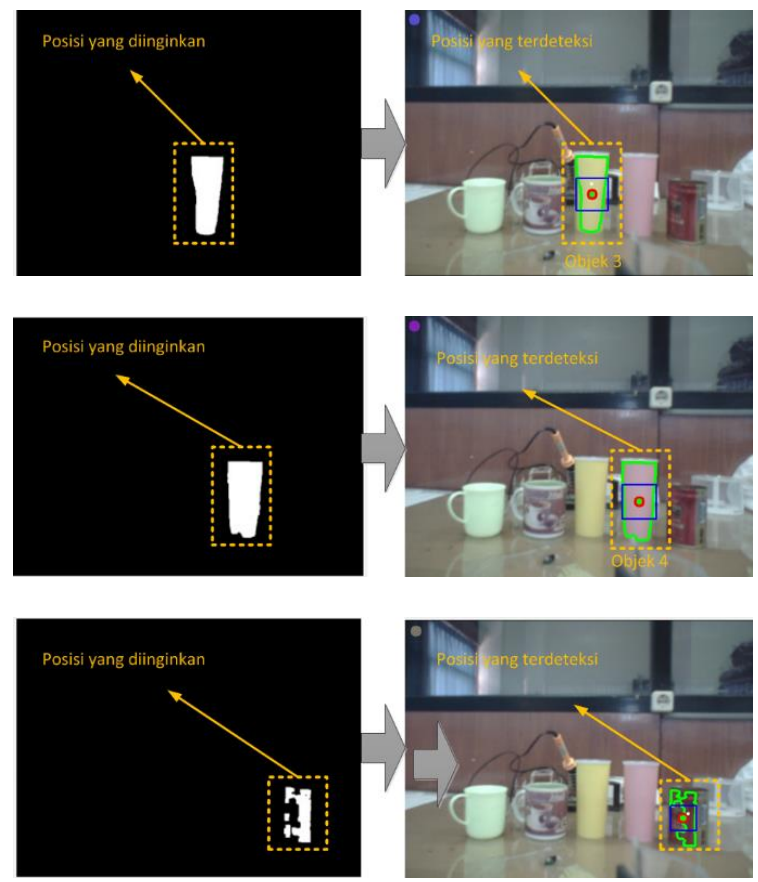

Gambar 6. Proses mendeteksi kontur dari beberapa objek di atas meja
Pengujian mendeteksi kontur objek dilakukan untuk mengetahui kemampuan sistem yang telah dirancang menggunakan kamera dalam mengekstraksi berbagai bentuk dan posisi objek di atas meja pada gambar hasil capture kamera pada layar monitor menggunakan perintah mouse click sebanyak 10 kali pemilihan pada masing-masing objek menggunakan metoda kode rantai. Proses pengujian mendeteksi kontur dari beberapa objek di atas meja ditunjukkan pada Gambar 6.

Posisi titik tengah objek ditentukan berdasarkan luasan kontur yang terbentuk, dimana kontur terbesar diasumsikan sebagai luasan terpilih sebagai objek yang ingin dideteksi. Didapatkan kesalahan rara-rata dalam mengekstraksi posisi tengah objek yang dilakukan untuk posisi koordinat $\mathrm{x}$ adalah 12,8 piksel dan koordinat y adalah 15,2 piksel dengan tingkat kesalahan $1,4 \%$.

\subsection{Pengujian Pengukuran Jarak Objek}

Pada pengujian ini bertujuan untuk mengetahui berapa jarak objek yang mampu diukur dengan menggunakan kamera dan sinar laser pointer. Pengujian dilakukan dengan cara meletakkan sebuah objek berupa gelas di depan kamera yang akan diamati.

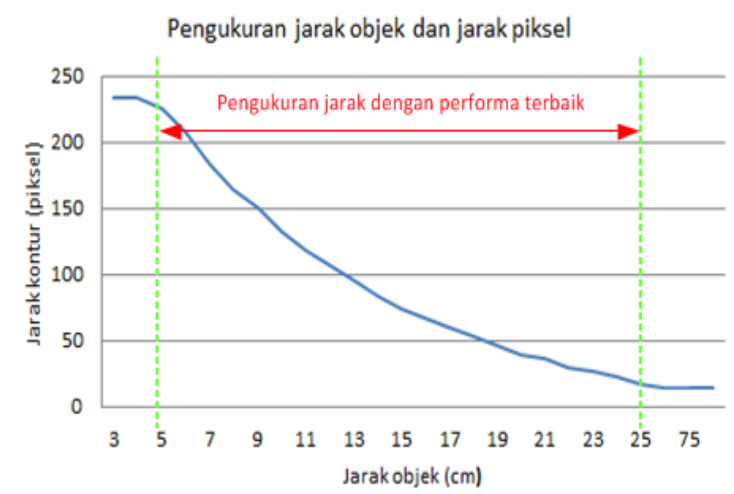

Gambar 7. Grafik hubungan jarak dan nilai selisih jarak

Hubungan antara nilai selisih jarak piksel dengan jarak dapat didekati dengan persamaan garis polinomial seperti yang ditunjukkan pada Gambar 7. Berdasarkan hasil dari pengujian hubungan jarak dan nilai selisih jarak piksel, dapat disimpulkan bahwa pengukuran jarak objek dengan menggunakan kamera memiliki performa yang baik pada jarak objek antara 5 sampai $25 \mathrm{~cm}$. 


\subsection{Pengujian Kendali Lengan Robot}

Pengujian ini bertujuan untuk menguji kecepatan kinerja sistem kendali yang telah dirancang dalam melakukan tugas untuk mengambil sebuah objek. Pengujian dilakukan dengan menggunakan sebuah objek berupa gelas di atas meja dengan jarak objek $21 \mathrm{~cm}$ dan sudut arah hadap kamera $\theta_{0}$ seperti yang ditunjukkan pada Gambar 8.

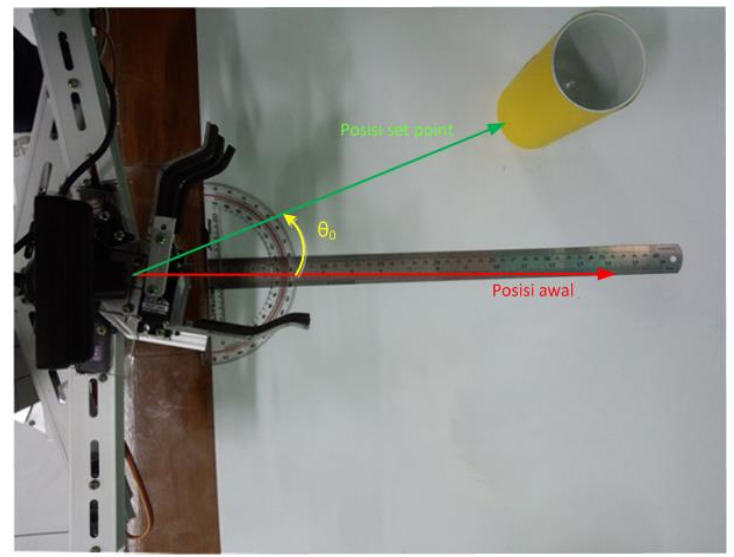

(a) Tampak Atas

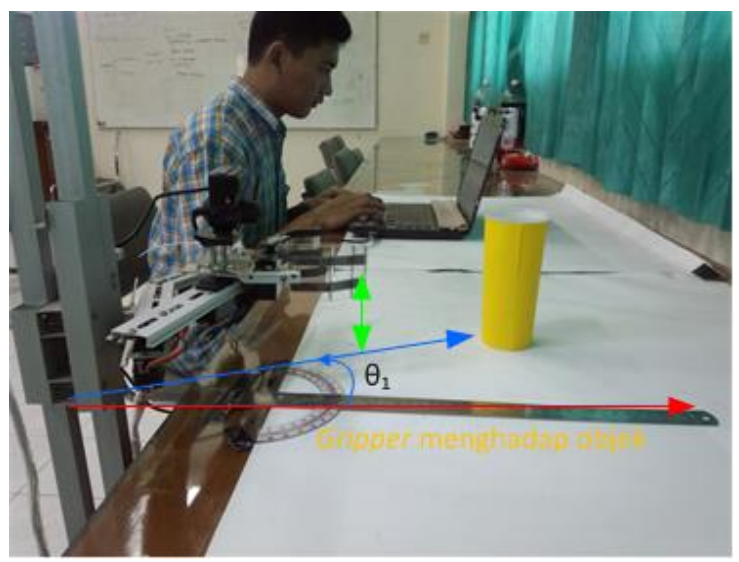

(b) Tampak Samping

Gambar 7. Pengujian kendali lengan robot

Pada posisi awal, lengan robot diatur dengan posisi objek berada di luas area pandangan kamera. Selanjutnya lengan robot akan bergerak menghadap ke sudut arah posisi objek hingga mencapai set point titik tengah kontur objek. Setelah posisi lengan robot sejajar dengan objek maka sensor akan mengukur jarak antara gripper dengan objek. Gripper pada lengan robot bergerak mendekat lalu menggenggam objek dan mengangkatnya lalu kembali ke posisi semula dengan objek tetap tergenggam. Selanjutnya, lengan akan mengarah ke sudut posisi akhir dan lengan akan memanjang untuk meletakkan objek yang telah digenggam untuk diletakkan di posisi akhir yang telah ditentukan.

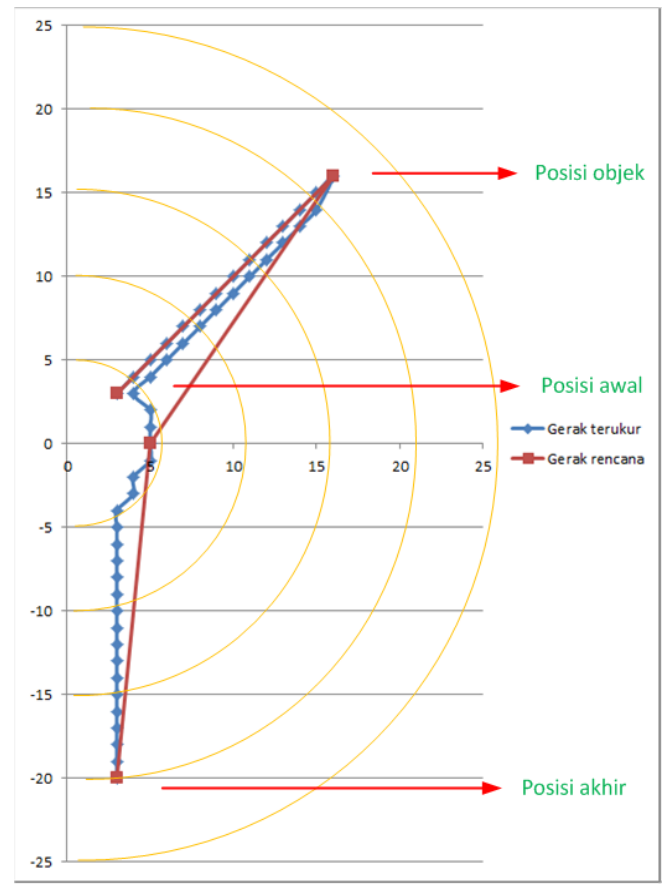

Gambar 8. Hasil pengujian kendali lengan robot

Pada pengujian kecepatan kinerja sistem kendali menggunakan manipulator lengan robot dengan cylindrical coordinat ketika menggambil sebuah objek di atas meja dari posisi awal sampai akhir memerlukan waktu 28,05 detik.

\section{KESIMPULAN}

Setelah dilakukan pengujian terhadap sistem yang dibangun dengan menggunakan metoda yang telah dirancang, dapat disimpulkan bahwa sistem lengan robot dapat mendeteksi posisi sebuah objek dan mengestimasi jarak objek tersebut dengan menggunakan vision sensor berupa kamera halaman. Metoda deteksi kontur digunakan sebagai algoritma untuk mendeteksi luas permukaan objek dengan cara mengekstraksi fitur permukaan objek yang memiliki warna spesifik memiliki nilai error rata-rata mencapai $1,4 \%$. Kamera sebagai instumentasi pengukur jarak objek yang telah didesain mampu mendeteksi jarak antara $5 \mathrm{~cm}$ sampai $25 \mathrm{~cm}$. Pada pengujian keseluruhan sistem ketika menggambil sebuah objek di atas meja memerlukan waktu rata-rata 28,05 detik. 


\section{DAFTAR PUSTAKA}

[1] Brault, Matthew W. "Americans with disabilities: 2010." Current population reports 7 (2012): 0-131.

[2] Feil-Seifer, David, and Maja J. Mataric. "Defining socially assistive robotics." Rehabilitation Robotics, 2005. ICORR 2005. 9th International Conference on. IEEE, 2005.

[3] Spenko, Matthew, Haoyong Yu, and Steven Dubowsky. "Robotic personal aids for mobility and monitoring for the elderly." IEEE Transactions on Neural Systems and Rehabilitation Engineering 14.3 (2006): 344-351.

[4] Graf, Birgit, et al. "Robotic home assistant Care-O-bot ${ }^{\circledR}$ 3-product vision and innovation platform." Advanced Robotics and its Social Impacts (ARSO), 2009 IEEE Workshop on. IEEE, 2009.

[5] Tsui, Katherine, et al. "Development and evaluation of a flexible interface for a wheelchair mounted robotic arm." Proceedings of the 3rd ACM/IEEE international conference on Human robot interaction. ACM, 2008.

[6] Huang, Tian, et al. "Planar parallel robot mechanism with two translational degrees of freedom." U.S. Patent No. 7,090,458. 15 Aug. 2006.

[7] Yanco, Holly. "Wheelesley: A robotic wheelchair system: Indoor navigation and user interface." Assistive technology and artificial intelligence (1998): 256-268.

[8] Simpson, Richard C., Daniel Poirot, and Francie Baxter. "The Hephaestus smart wheelchair system." IEEE Transactions on Neural Systems and Rehabilitation Engineering 10.2 (2002): 118-122.

[9] Topping, Michael J., and Jane K. Smith. "The development of handy 1. A robotic system to assist the severely disabled." Technology and Disability 10.2 (1999): 95-105.

[10] Saxena, Ashutosh, et al. "A vision-based system for grasping novel objects in cluttered environments." Robotics research. Springer Berlin Heidelberg, 2010. 337-348.

[11] Kouskouridas, Rigas, Angelos Amanatiadis, and Antonios Gasteratos.
"Guiding a robotic gripper by visual feedback for object manipulation tasks." Mechatronics (ICM), 2011 IEEE International Conference on. IEEE, 2011.

[12] Wang, Jie, et al. "Research on Hand-Eye Robot." Mechatronics and Automation, Proceedings of the 2006 IEEE International Conference on. IEEE, 2006.

[13] Song, Won-Kyung, Heyoung Lee, and Zeungnam Bien. "KARES: Intelligent wheelchair-mounted robotic arm system using vision and force sensor." Robotics and Autonomous Systems 28.1 (1999): 8394.

[14] Grebenstein, Markus, et al. "The DLR hand arm system." Robotics and Automation (ICRA), 2011 IEEE International Conference on. IEEE, 2011.

[15] Sanchez-Lopez, Jose Ruben, Antonio Marin-Hernandez, and Elvia R. PalaciosHernandez. "Visual detection, tracking and pose estimation of a robotic arm end effector." Proc. Robotics Summer Meeting (Veracruz, Mexico, 27-28 June 2011). 2011.

\section{Biodata Penulis}

Riky Tri Yunardi, lahir di kota Jambi pada tahun 1989. Menamatkan jenjang pendidikan S1 Teknik Elektro di Universitas Brawijaya, Malang tahun 2011. Pendidik S2 Teknik Elektro ditempuh di Institut Teknologi Sepuluh Nopember, Surabaya tahun 2014, melalui program Beasiswa Unggulan Tahun 2012 Kemendikbud. Sekarang bekerja sebagai dosen di Departemen Teknik, Fakultas Vokasi, Universitas Airlangga. Ketertarikan penelitian di bidang teknik elektronika, robotika dan sistem otomasi.

Ronny Mardiyanto, lahir di kota Madiun pada tahun 1981. Menamatkan jenjang pendidikan S1 Teknik Elektro di ITS Surabaya tahun 2003. Pendidik S2 Teknik Elektro ditempuh di ITB Bandung tahun 2006. Dan Pendidik S3 di Saga University, Jepang tahun 2011. Sekarang bekerja sebagai dosen di Departemen Teknik Elekro, ITS Surabaya. Ketertarikan penelitian di bidang robotika, human machine interaction dan machine vision. 